\title{
Development Training Employers' Group Bamboo
}

\author{
Siti Khadijah Hidayati Nasution ${ }^{1)}$, Sinar Indra Kesuma ${ }^{2)}$, Suzanna Fitriany Sitepu ${ }^{3)}$ \\ ${ }^{123}$ Fakultas Pertanian, Universitas Sumatera Utara \\ email: rajabulan61@yahoo.com
}

\begin{abstract}
Bamboo craft employers' group (Mr. Gunawan and Irwansyah), both located in the Village of West Rambung, District of South Binjai, Binjai. Both drying bamboo by using sunlight so that the quality is low if production during bad weather or rain, employers also do not yet know how to control the quality of the end product of bamboo, not knowing about the Patent/IPR, has not been able to make bookkeeping, and difficulty getting bamboo. Therefore, a team of lecturer from the Department of Agribusiness and Agroecotechnologi USU nurture small businesses through service activities: manufacture Oven Dryer, technology training drying bamboo by using Oven Dryer, training Quality Circles, training on Patent and IPR, making training books, and training Aquaculture Bamboo. The result: the entrepreneur has been able to use the oven dryer to dry the bamboo, to understand how to control the quality of the final product bamboo, know about the patent and intellectual property rights, are able to make bookkeeping, and know the techniques of bamboo cultivation right and can produce bamboo production / productivity and a high quality and sustainable. With the completion of this activity, both partners can develop their business and ultimately increase revenue. Outputs training: Oven Dryer, appropriate technology module bamboo drying, and appropriate technology module bamboo cultivation.
\end{abstract}

Keywords: small entrepreneurs, bamboo craft, training, drying oven

\section{PENDAhuluan}

\section{Latar Belakang}

KotaBinjai merupakan suatu daerah di

Provinsi Sumatera Utara yang memiliki banyak usaha kerajinan dan kelompok pengusaha kecil. Salah satu daerahnya adalah Kelurahan Rambung Barat,Kecamatan Binjai Selatan, KotaBinjai, Provinsi Sumatera Utara memiliki banyak pengusaha kerajinan bambu. Produk-produk yang dihasilkan para pengrajin bambu di daerah ini antara lain adalah aneka kap lampu,keranjang parsel, vas bunga, talam, mebel, tampah, sangkar burung, dan lain-lain. Salah satu pengusaha yang juga merupakan ketua kelompok yaitu Bapak Gunawan yang telah melakoni usaha ini selama puluhan tahun.Bapak ini merupakan generasi ke 2 yang melanjutkan usaha ini.

Bapak Gunawan telah memiliki tempat yang merupakan rumah yang dijadikan untuk tempat gudang, sanggar pembuatan,tempat pelatihan, dan juga digunakan pengrajin untuk berkumpul mengerjakan pesanan ataupun membuat produk ataupun tempat produkproduk yang akan dipamerkan yaitu di Jl.Jambi 4, Gg. Jambi 4, No. 6 Kelurahan Rambung Barat, Kecamatan Binjai Selatan,
Kota Binjai. Kelompok yang dipimpin oleh Bapak Gunawan ini dinamakan Kelompok Bunga Matahari.

Kelompok Bunga Matahari memiliki anggota 5 orang.Omzet setiap bulannya antara Rp. 6-7 juta, dimana keuntungannya sekitar 30-50\%.Masa-masa pemasaran atau permintaan yang sunyi yaitu pada saat selesai Tahun Baru dan sesudah Lebaran. Peningkatan atau omzet yang banyak terjadi pada saat mendekati Lebaran dan Tahun Baru.

Kapasitas produksinya antara lain adalah kap lampu sebanyak 50 buah/bulan. Keranjang parsel sebanyak 100/2 bulan. Alatalat yang dimiliki adalah mesin bor duduk sebanyak 1 unit, gergaji, parang, pisau, tang, gunting rotan, gunting biasa, bor tembak 1 unit, dan kompor gas.

Manajemen usaha yang dilakukan masih tradisional.Kedua pengusaha ini masih belum ada melakukan pembukuan terhadap uang keluar dan uang masuk dari usaha kerajinan bambu mereka. Pemasaran produk dilakukan ke daerah Medan, Binjai,Tapanuli Selatan dan Pematang Siantar. Pada saat wawancara pengusaha Bapak Gunawan mengatakan bahwa pernah ada permintaan dari Malaysia, 
tapi tidak dapat terpenuhi karena keterbatasan alat dan pengrajin sehingga tidak dapat menerima permintaan kontrak dari Malaysia tersebut.

\section{Permasalahan Mitra}

Permasalahan yang dihadapi mitra (pengusaha kerajinan bambu) adalah bahan baku yaitu bambu mulai sulit didapatkan dan produksi/produktivitas dan kwalitasnya rendah, hanya mengeringkan bambu dengan sinar matahari sehingga mutu sangat rendah jika melakukan produksi pada saat cuaca kurang baik/hujan, belum memahami cara pengendalian mutu (gugus kendali mutu) terhadap produk akhir bambu, belum memahami pengetahuan mengenai Paten dan HKI, serta belum mampu membuat pembukuan yang baik dan benar mengenai uang keluar dan uang masuk

\section{Target}

Target dari pelatihan yang dilakukan dalam pengabdian kepada masyarakat ini adalah: Pengusaha mampu melakukan cara pengeringan bambu dengan menggunakan Oven Pengering 5 Rak dengan energi gas elpiji atau minyak lampu, Pengusaha memahami cara pengendalian mutu (gugus kendali mutu) terhadap produk akhir bambu, Pengusaha memahami pengetahuan mengenai Paten dan HKI, Pengusaha mampu membuat pembukuan yang baik dan benar mengenai uang keluar dan uang masuk, .Petani bambu memahami dan mau menerapkan teknik budidaya bambu yang tepat dan sesuai dengan paket teknologi tepat guna budidaya bambu, yaitu yang dapat menghasilkan bambu dengan produksi/ produktivitas dan kwalitas yang tinggi dan berkelanjutan.

\section{Luaran}

Luaran dari serangkaian pelatihan yang dilakukan dalam pengabdian kepada masyarakat ini adalah: 1. Alat Pengering (Oven Pengering 5 Rak) sebanyak 2 unit, 2.Modul teknologi tepat guna pengeringan bambu, dan 3.Modul teknologi tepat guna budidaya bambu.

\section{METODE PENELITIAN}

Metode pelaksanaan pelatihan untuk mengatasi permasalahan mitra terdiri dari 6 langkah yang terdiri dari: 1 pembuatan Oven
Pengering 5 Rak, dan 5 jenis pelatihan yaitu pelatihan teknologi pengeringan bambu dengan menggunakan Oven Pengering 5 Rak, pelatihan Gugus Kendali Mutu, pelatihan pengetahuan mengenai Paten dan HKI, pelatihan pembukuan yang baik dan benar mengenai uang keluar dan uang masuk, dan pelatihan budidaya bambu kepada petani/pengusaha kerajinan bambu. Partisipasi mitra (pengusaha kerajinan bambu) adalah bersedia untuk dilatih dan menyediakan waktu untuk pelatihan, bersedia untuk menyediakan tempat pelatihan, bersedia untuk melakukan semua hasil pelatihan yang telah diadakan, bersedia untuk dievaluasi setiap 3 bulan sekali.

\section{HASIL DAN PEMBAHASAN}

\section{Pembuatan Oven Pengering 5 Rak}

Pembuatan Oven Pengering 5 Rak telah dilakukan oleh Bapak Ir. Terip Karo-Karo, M.Si selaku pengusaha pembuat alat-alat teknologi tepat guna. Oven pengering yang dibuat berjumlah dua unit, dengan ukuran masing-masing $80 \mathrm{~cm} \times 45 \mathrm{~cm} \times 160 \mathrm{~cm}$, dengan kapasitas $10-15 \mathrm{~kg}$ serta terbuat dari bahan seng dan stainless. Penyerahan oven pengering dilakukan dalam dua tahap. Setelah alat Oven Pengering 5 Rak pertama selesai, langsung dilakukan serah terima alat kepada pengusaha kerajinan bambu yang pertama yaitu Bapak Gunawan pada tanggal 2 Juli 2016. Pada tahap kedua yaitu pada tanggal 2 Agustus 2016, dilakukan penyerahan Oven Pengering 5 Rak kepada pengusaha kerajinan bambu yang kedua yaitu Bapak Irwansyah.

Sebelum adanya kegiatan pemberian Oven Pengering 5 Rak, pengusaha kerajinan bambu hanya mampu mengeringkan bambu dengan sinar matahari saja sehingga jika cuaca buruk atau musim hujan maka pengeringan dengan sinar matahari tidak dapat diharapkan lagi. Apabila bambu tidak kering atau pengeringannya tidak sempurna, maka kerajinan bambu yang dihasilkan akan rendah mutunya karena bambu akan berjamur dan mudah berserbuk. Dengan pemberian Oven Pengering 5 Rak tersebut, pengeringan bambu tidak terkendala lagi sehingga produksi kerajinan bambu dengan mutu yang baik tetap dapat dilakukan walaupun pada musim hujan. Hasil yang diperoleh dari pembuatan dan pemberian Oven Pengering 5 
Nasution, SKH. et al. Development Training Employers' Group Bamboo

Rak ini pengusaha kerajinan bambu merasa sangat senang dan terbantu serta berterimakasih kepada para Instruktur/tim pelatih dari USU. Hal ini diketahui dari hasil wawancara bahwa mereka sangat senang sekali dan terbantu karena baru sekali ini mereka menerima bantuan dari pemerintah (Kemenristek Dikti melalui LPPM USU). Selama puluhan tahun berkiprah dalam bisnis pembuatan kerajinan bambu, belum pernah sekalipun Bapak Gunawan dan Bapak Irwansyah mendapat bantuan dari instansi manapun, baik pemerintah maupun swasta.

\section{Pelatihan Teknologi Pengeringan Bambu dengan Menggunakan Oven Pengering 5 Rak}

Kegiatan pelatihan pengeringan bambu dengan menggunakan Oven Pengering 5 Rak ini difasilitasi oleh Ir. Terip Karo-Karo, M.Si. Selaku instruktur, Bapak Terip Karo-Karo menjelaskan tentang cara penggunaan Oven Pengering 5 Rak. Penggunaan oven ini bisa dengan menggunakan energi atau panas yang berasal dari kompor minyak lampu ataupun kompor gas. Pada saat pengeringan bambu, api kompor diusahakan sedang dan suhu dikontrol tetap berkisar antar $70-80^{\circ} \mathrm{C}$ dengan lama pengeringan tergantung pada kadar air bambu, ketebalan dan ukuran bambu. Untuk bambu yang tipis dan kecil, waktu yang dibutuhkan hanya 30 menit. Bambu yang tebal dan sedang, waktu yang dibutuhkan adalah sekitar 3 jam. Sedangkan bambu yang tebal dan besar, waktu yang dibutuhkan kurang lebih 4 jam. Peserta menanggapinya dengan antusias, terlihat dengan banyaknya pertanyaan terkait cara pengeringan bambu dengan menggunakan Oven Pengering 5 Rak yang ditujukan kepada pengusaha pembuat oven pengering, dan pengusaha kerajinan bambu sangat antusias pula untuk mempraktekkannya langsung. Dalam kegiatan pelatihan ini, instruktur memberi kesempatan bagi peserta yaitu pengusaha kerajinan bambu untuk mempraktekkannya secara langsung. Hasil yang diperoleh dari pelatihan ini pengusaha kerajinan bambu menjadi mampu melakukan teknologi pengeringan bambu dengan menggunakan Oven Pengering 5 Rak dengan energi gas elpiji ataupun minyak lampu.

\section{Pelatihan Gugus Kendali Mutu}

Instruktur Pelatihan Gugus Kendali Mutu ini adalah Ir. Sinar Indra Kesuma, M.Si. Gugus Kendali Mutu adalah suatu sistem dalam manajemen usaha yang ditujukan untuk meningkatkan efisiensi, produktivitas dan mutu produksi, dalalm rangka meningkatkan daya-saing produk yang dihasilkan sehingga mutu produk mampu menjadi pemenang dan leader di pasaran yang akhirnya menghasilkan keuntungan bagi pengusaha ataupun perusahaan. Pada saat pelatihan dilakukan sesi tanya jawab, diskusi dan sharing antara peserta yang teridiri dari pengusaha kerajinan bambu dengan instruktur. Hasil yang diperoleh dari pelatihan ini pengusaha kerajinan bambu telah memahami cara pengendalian mutu (gugus kendali mutu) terhadap produk akhir bambu.

\section{Pelatihan Paten dan HKI}

Kegiatan Pelatihan Paten dan HKI ini difasilitasi oleh Instruktur Ir. Sinar Indra Kesuma, M.Si. Pelatihan Paten dan HKI ini dimaksudkan agar timbul kesadaran pengusaha kerajinan bambu untuk menjaga desain produk yang mereka buat sendiri agar terlindungi dan juga agar pengusaha kerajinan bambu tidak meniru desain produk produsen lain yang telah memiliki sertifikat paten karena akan mendapat sanksi hukum. Pada saat pelatihan dilakukan sesi tanya jawab dan diskusi dengan peserta yang terdiri dari pengusaha kerajinan bambu.

\section{Pelatihan Pembukuan}

Pelatihan pembukuan yang baik dan benar menganai uang keluar dan uang masuk disampaikan oleh Instruktur Siti Khadijah $\mathrm{H}$. Nasution., S.P, M.Si. Dari hasil wawancara diketahui bahwa kedua pengusaha kerajinan bambu yaitu Bapak Gunawan dan Bapak Irwansyah belum pernah membuat pembukuan mengenai uang keluar dan uang masuk. Pengusaha tidak mengetahui cara membuat pembukuan yang baik dan benar. Pada pelatihan ini dijelaskan dan dilatih agar pengusaha terbiasa untuk mencatat semua uang keluar dan uang masuk setiap harinya dan nantinya diakumulasikan pada akhir bulan agar diperoleh informasi keuangan dari usaha yang ditekuninya dan berguna sebagai bahan analisa dan interpretasi untuk 
mengadakan evaluasi terhadap diri sendiri. Pada pelatihan ini peserta dilatiah membuat Jurnal Umum, Buku Besar, Laporan Laba Rugi, Perubahan Kenaikan Modal, dan Neraca. Di akhir pelatihan juga disampaikan dan ditekankan bahwa dengan adanya pembukuan yang baik dan benar, maka akan membantu/mempermudah pengusaha untuk memperoleh bantuan lunak dari berbagai instansi seperti: Pertamina, PLN, berbagai PTPN, dan lain-lain. Karena dengan adanya pembukuan yang baik dan benar dari suatu unit usaha, maka hal ini akan menjadi dasar pengambilan keputusan bagi pihak-pihak yang ingin memberikan bantuan ataupun yang akan menginvestasikan dananya pada usaha tersebut apakah usaha tersebut layak atau tidak untuk diberi bantuan atau untuk diinvestasikan. Hal ini membuat pengusaha menjadi termotivasi untuk membuat pembukuan yang baik dan benar. Hasil yang diperoleh dari pelatihan ini, pengusaha kerajinan bambu telah memahami cara membuat pembukuan yang baik dan benar mengenai uang keluar dan uang masuk.

\section{Pelatihan Budidaya Bambu}

Pelatihan Budidaya Bambu dilaksanakan oleh Instruktur Ir. Suzanna Fitriany Sitepu, M.Si. Instruktur menjelaskan tentang bagaimana teknik budidaya bambu yang baik dan tepat yang sesuai dengan paket teknologi tepat guna budidaya bambu sehingga produksi/produktivitas dan kwalitas bambu tinggi dan berkelanjutan, yaitu dengan: pemilihan jenis bambu yang sesuai dengan iklim dan kondisi lahan, mengikuti petunjuk teknis pembibitan bambu yang baik, pengaturan jarak tanam yang baik, waktu tanam yang tepat, pemeliharaan yang tepat yaitu meliputi: penyulaman, penyiangan, pemangkasan, pemupukan, penjarangan, pengaturan struktur dan komposisi batang dalam rumpun, pengaturan drainase, dan menerapkan teknik penebangan Tebang Pilih. Dengan menerapkan teknik Tebang Pilih, tanaman bambu tidak akan habis sekali panen tetapi akan berkelanjutan karena hanya tanaman yang sudah memenuhi syarat saja yamg dipanen sedangkan yang masih belum memenuhi syarat dibiarkan sampai besar dan memenuhi syarat baru dipanen. Selama pelatihan berlangsung, terlihat peserta begitu antusias. Hal ini terlihat dari banyaknya pertanyaan maupun masukan atau sharing dari para peserta pada sesi tanya jawab dan diskusi dengan peserta yang terdiri dari para petani bambu sekaligus merupakan pengrajin bambu. Dari pelatihan ini petani/pengusaha kerajinan bambu telah memahami bagaimana teknik budidaya bambu yang tepat sehingga produksi/produktivitas dan kwalitas bambu tinggi dan berkelanjutan. Dan dari pelatihan ini petani/pengusaha kerajinan bambu juga tergugah untuk menerapkan teknik budidaya bambu yang tepat mengingat semakin meningkatnya kebutuhan bambu untuk beraneka ragam keperluan, salah satunya yaitu sebagai bahan baku kerajinan bambu.

\section{KESIMPULAN}

Dari serangkaian kegiatan pengabdian yang telah dilaksanakan, maka dapat disimpulkan beberapa hal sebagai berikut: 1.Pengusaha kerajinan bambu telah mampu menggunakan Oven Pengering 5 Rak untuk mengeringkan bambunya, 2.Pengusaha kerajinan bambu telah memahami cara pengendalian mutu terhadap produk akhir bambu, 3. Pengusaha kerajinan bambu telah memahami pengetahuan mengenai Paten dan HKI, 4. Pengusaha kerajinan bambu telah memahami cara membuat pembukuan yang baik dan benar mengenai uang keluar dan uang masuk, 5. Pengusaha kerajinan bambu/ petani telah mamahami teknik budidaya bambu yang tepat dan dapat menghasilkan bambu dengan produksi/produktivitas dan kwalitas yang tinggi dan berkelanjutan, dan 6.pengusaha kerajinan bambu merasa senang dan terbantu dengan adanya pembinaan dan alat-alat dari tim pelaksana pengabdian USU, dan masih mengharapkan untuk dibina lagi

\section{REFERENSI}

Anonim. 2012. Bambu Indonesia. Departemen Kehutanan. http:// file:// D:/dataku/ Bambu/ dep.Kehutanan.htm

Anonim. 2013. Buku Panduan Hak Kekayaan Intelektual. Direktorat Jenderal Hak Kekayaan Intelektual Kementerian Hukum dan Hak Asasi Manusia R.I. Tangerang.

Anonim. 2013. Panduan Pengenalan HKI, Klinik Konsultasi HKI. Direktorat Jenderal Industri Kecil dan Menengah, 
Nasution, SKH. et al. Development Training Employers' Group Bamboo

Departemen Perindustrian. Jakarta. http://etutorial.dgip.go.id/wpcontent/upl oads/brosur/panduan-2013.pdf

Circle Headquarters, Q.C., JUSE. 1984. Gugus Kendali Mutu: Prinsip-Prinsip Dasar tentang Kendali Mutu. PPM.

Hadibroto, S., Dachnial Lubis, dan Sudradjat Sukadam. 1991. Dasar-Dasar Akuntansi. Lembaga Penelitian, Pendidikan dan Penerangan Ekonomi Sosial (LP3ES). Jakarta.

Nugroho, A. 2012. Meraup untung Budidaya Rebung. Pustaka Baru Press. Yogyakarta.
Olga L, Crocker, Syiril Charney, Johny SL Chin. Gugus Kendali Mutu, Pedoman, Partisipasi, dan Produktivitas. Bumi Aksara. Jakarta.

Saidin. 2013. Aspek Hukum Hak Kekayaan Intelektual (Intelectual Property Rights). Rajawali Press. Jakarta.

Sutiyono. 1996. Budidaya Bambu. Pusat Litbang Hasil Hutan. Bogor. 